\title{
The Changing Role of Pathology in Breast Cancer Diagnosis and Treatment
}

\author{
Anthony S.-Y. Leong ${ }^{a}$ Zhengping Zhuang ${ }^{b}$ \\ ${ }^{a}$ Hunter Area Pathology Service, Anatomical Pathology, University of Newcastle, Newcastle, N.S.W., Australia; \\ ${ }^{b}$ Molecular Pathogenesis Unit, National Institutes of Health, Bethesda, Md., USA
}

\section{Key Words}

Breast cancer $\cdot$ Immunohistochemistry $\cdot$ Molecular technology $\cdot$ Biomarkers · Prognosis · Predictive markers • Proteomics $\cdot$ Drug discovery $\cdot$ Stem cells

\begin{abstract}
Pathological examination has been the gold standard for diagnosis in cancer and its role has also included the elucidation of etiology, pathogenesis, clinicopathological correlation, and prognostication. The advent of newer technologies and the realization that breast cancer is heterogeneous has shifted the focus to prognostication, with increased attention being paid to the identification of morphological features and immunohistochemical markers of prognostic relevance. However, despite the massive efforts invested in the identification of immunohistochemical biomarkers in breast cancer the majority have not proven to be of value in multivariate analyses and only estrogen receptor, progesterone receptor, and Her2/neu expression have remained essential components of pathological examination. These 3 markers were initially employed for prognostication but their role in treatment also rendered them of predictive value. Newer molecular methods, especially high-throughput technologies, have shown that even morphologically similar sub-
\end{abstract}

types of breast cancer can show molecular heterogeneity; moreover, infiltrating ductal carcinoma can be separated into at least 4 molecular subtypes designated luminal (ER+, $\mathrm{PR}+$, and Her2/neu-), Her2 overexpressing (ER-, PR-, and Her2/neu+), basal-like (ER-, PR-, Her2/neu-, and CK5/6+, EGFR+), and normal breast-like (ER-, PR-, and Her2/neu-), each with different clinical outcomes. The importance of proliferative gene expression in these subtypes has been demonstrated and surrogate immunohistochemical markers include ER, PR, Her2/neu, and Ki67 for the more expensive molecular tests. Molecular technologies, importantly, have not only provided further insights into the heterogeneity of breast cancer but have also opened new avenues for treatment through the identification of signaling molecules important in the proliferation and survival of the neoplastic cells. The treatment of cancer thus shifts from the conventional approach of 'one size fits all' to one of personalized treatment tailored to the specific characteristics of the tumor. Pathologists continue to play their traditional role in diagnosis but, as purveyors of the excised tissue, pathologists now have the additional role of identifying biomarkers responsive to therapeutic manipulation, thus playing an inextricable role as diagnostic oncologists in the management of breast cancer.

Copyright $\odot 2011$ S. Karger AG, Basel

\section{KARGER}

Fax +41613061234

E-Mail karger@karger.ch

www.karger.com
(C) 2011 S. Karger AG, Basel

Accessible online at: www.karger.com/pat
Dr. Anthony S.-Y. Leong, MB, BS, MD

Hunter Area Pathology Service

Locked Bag 1, HRMC

Newcastle, NSW 2310 (Australia)

E-Mail aleong@mail.newcastle.edu.au 


\section{Introduction}

Morphological examination remains the mainstay of diagnosis; this is particularly so in the case of neoplastic diseases. Through the examination of gross and microscopic features, pathologists also determine etiology, attempt to predict behavior, and provide a correlation with the clinical presentation of the disease. This was initially performed on excised specimens and based on simple gross observations such as tumor size, extent of involvement, presence of necrosis, and presence of metastasis or vascular invasion. The introduction of less invasive techniques resulted in smaller samples of diseased tissue becoming available for examination, and the prediction of tumor behavior became strongly centered on microscopic features such as cell type, extent of differentiation, mitotic activity, microscopic lymphovascular invasion, lymphoplasmacytic reaction, metastasis, and the nature of the tumor borders. Tumor grading based on the level of cellular differentiation or resemblance to its normal counterpart, and staging based on the extent of involvement of the tumor and spread, was performed in order to prognosticate. Often, subsequent management of the cancer was predicated on these prognostic features. Some of the macroscopic and microscopic parameters proved to be of prognostic value while others such as tumor grade tended to be superseded by stage. The ability to predict behavior was thus relatively inaccurate but prognostication, in addition to diagnosis, was very much an integral function of pathological examination. The role of the pathologist as a diagnostic oncologist thus involves the complete spectrum or continuum of cancer care and extends from prevention and screening through diagnosis to prognosis and prediction of the therapeutic response and monitoring of the disease. This role has now been extended to include the molecular aspects that allow greater insights into the pathogenesis and treatment of cancer.

This emerging role for pathology is exemplified in the case of breast cancer especially with the realization that breast cancer is not a single disease, and subgroups of breast cancer with different clinical outcomes can be morphologically identified. With the development of sophisticated techniques of examination, pathologists have continued to seek biological information regarding the different types of breast cancer that are linked to clinical data such as overall survival, disease-free survival, or quality of life, and they have continued to develop methods for the earlier detection of tumors and metastases. Through their unique and pivotal role as keepers and purveyors of excised tissues, pathologists have extended their role into the area of translational research, employing new technologies to examine the molecular complexities of breast cancer and relate the biological heterogeneity to prognosis and treatment. Furthermore, the development of newer forms of cancer treatment, both complimentary and supplementary to conventional treatment modalities, as well as the desire to provide personalized medicine in place of the traditional 'one size fits all' approach has resulted in this paradigm shift in breast cancer.

\section{The Conventional Role of Pathology}

Using microscopic observations based on tubule formation, mitotic activity, and cellular pleomorphism, the Scarff-Bloom-Richardson grading system for breast cancer was developed [1]. Subsequent refinement and incorporation into the Nottingham Prognostic Index [2] produced a robust scoring system that predicted long-term survival for patients with breast cancer. This and other systems have been the basis on which most clinical management decisions concerning adjuvant therapy are made [3-5]. With conventional treatment modalities of surgery, chemotherapy, and radiation, however, it became evident that many patients relapse after treatment and many who qualify for established treatment protocols or regimes receive no benefit from the treatment. It is also interesting to note that the relative value of the prognostic variables employed in the Nottingham Prognostic Index vary with time after the initial diagnosis; a prognostic factor that is highly significant for outcome in the first year after diagnosis may have little relevance after 5 years. In a long-term study of a cohort of 464 patients with breast cancer, it was found that tumor diameter, axillary lymph node status, glandular formation, and the proportion of intraductal growth were of prognostic value for up to 5 years; the mitotic index was significant the first 2 years, but histological grade and morphometric nuclear factors had short-term value only [6]. Subsequent studies have confirmed the value of lymph node status, tumor diameter, and histological differentiation, stage, lymph, and blood vessel invasion as prognostic factors employed in the Nottingham prognostic index which combines the strongest of these factors [reviewed in 7].

The limitations of chemotherapy, especially the narrow therapeutic index, and the lack of discrimination of both chemotherapy and radiotherapy for cancerous and noncancerous cells have prompted the search for a great- 
er target-directed approach to cancer treatment. With the detailed unraveling of oncogenic pathways and tumor cell metabolism, the largely empirical chemotherapeutic approach to breast cancer has yielded to the realization that the disease is very heterogeneous. There is a pressing need to improve the prediction of tumor response and to better define those patients who will benefit from specific forms of treatment as well as to find ways to counter resistance, i.e. cancer therapy should be personalized or specifically tailored to the patient. Furthermore, besides the unnecessary costs and exposure of some patients to the complications and dangers of the treatment, it is likely that the empirical use of similar therapies in all patients may dilute the evidence of drug effectiveness in the specific subgroup in which the drug may in fact exhibit great efficacy.

\section{Prognostic and Predictive Markers}

Prognostic indicators can be defined as those data identified at the time of diagnosis that relate or predict the clinical outcome unrelated to adjuvant therapy. Predictive indicators, on the other hand, are those related to the degree or extent of response to the therapy administered. Clearly, some indicators can be both prognostic and predictive in nature.

In the late 1980s and through the 1990s, a great deal of effort was expended into the identification of biomarkers in breast cancer. The availability of sensitive immunohistochemical techniques and specific antibodies made the task easier and a variety of biomarkers were studied including the protein gene products of various growth factors and their receptors, hormone receptors, epidermal growth factor and its receptors, tumor suppressor genes, tumor-host interaction factors including angiogenesis factors, cathepsin D, matrix metalloproteinases, plasminogen activators, adhesion molecules, and multidrug resistance genes [reviewed in 8]. Ideal biological indices that are clinically relevant should provide information about etiology/causation, allow the assessment of future risk for the patient or her family, or directly influence treatment, and they should be relevant to prognosis. Many described biological factors appear to have prognostic relevance when studied retrospectively in univariate analyses, but such information may prove to be of limited use unless it is shown to be independently relevant in multivariate analysis [9]. The relative value of various prognostic factors also varies with time after the initial diagnosis; a prognostic factor that is highly significant for the outcome in the first year after diagnosis may have little relevance after 5 years. Of the many early biological markers studied, only estrogen receptor (ER), progesterone receptor (PR), and Her2 have been routinely employed in the management of breast cancer [10], making the assessment of these markers mandatory.

\section{$E R$ and $P R$}

The benefit of bilateral oophorectomy for the treatment of premenopausal breast cancer has long been recognized and the use of antiestrogen therapy for patients with breast cancer expressing ER represents the first selective targeted therapy in oncology [11-14].

The 2 isoforms of ER, i.e. ER $\alpha$ and ER $\beta$, are encoded by genes on $6 \mathrm{q} 25.1$ and $14 \mathrm{q} 22-\mathrm{q} 24$, respectively. While cellular response is dependent on the relative expression of the 2 receptors, ER $\alpha$ is the only clinically useful receptor as ER $\beta$ is scanty and sensitive antibodies to this molecule are currently not available. $\mathrm{ER} \alpha$ is a $65-\mathrm{kDa}$ nuclear receptor whose primary ligand is $17-\beta$-estradiol. Binding by ligand stimulates dimerization with subsequent binding to specific DNA sequences to induce gene transcription and thereby a cellular response. This action can be tempered by either blocking the receptor or depriving it of circulating ligand. Tamoxifen is the first of the selective ER modulators that can produce both agonistic and antagonistic effects on ER $\alpha$ in different tissues. It has reduced the risk of the recurrence of breast cancer within 5 years by $40 \%$ and the overall breast cancer-specific mortality by $31 \%$ [11]. Aromatase inhibitors which inhibit the conversion of precursor molecules to estradiol are alternative treatments. Interestingly, the absence of ER has been shown to indicate a good response to chemotherapy particularly in the neoadjuvant setting where pathological complete responses of $21-33 \%$ have been seen in ERnegative tumors and in only $7-8 \%$ of ER-positive tumors $[12,13]$.

The PR also exists as 2 isoforms, i.e. PR $\alpha$ and PR $\beta$, encoded by the gene on chromosome 1. Currently a distinction between these isoforms in tissue sections is not possible as the antibodies available are to the N-terminal portion common to both isoforms. The expression of PR is strongly dependent on estrogen and is thus rarely seen in ER-negative tumors. In the adjuvant setting of tamoxifen versus controls, PR expression is strongly prognostic but has little predictive value [14] in that those with a 'poor' PR status have worse outcomes than do PR-positive patients on tamoxifen; however, the relative benefit of tamoxifen is similar in both subgroups $[11,14]$. There is also a strong relationship between PR status and progno- 
sis in patients on endocrine therapy as was clearly shown in the adjuvant trials where recurrence after 5 years of anastrozole (aromatase inhibitor) treatment was $14 \%$ in those with 'low' expressing tumors compared to $<4 \%$ in patients with 'high' expressing tumors [15].

Both ER and PR are assessed by immunohistochemistry but consistency and reproducibility have been plagued by a variety of factors, many beyond the control of the laboratory, that influence the preservation of antigen in paraffin-embedded sections $[16,17]$. The recent scandal in Newfoundland, Canada, concerning testing for hormone receptors and HER2 attests to the problems associated with consistency and reproducibility in the area of quantitative immunohistochemistry [18]. The problem encountered in this Canadian province was anticipated by the joint American Society of Clinical Oncology and the College of American Pathologists recommendations which set a minimum and maximum duration of fixation of tissues prior to immunohistochemical analysis for these markers [19]. However, these are only preliminary guidelines to ensure the consistency and standardization of the many analytical variables that are critical to the demonstration of tissue antigens that would otherwise impede the use of immunohistochemistry in a quantitative manner $[16,17,20]$. Interpretation remains another problem and several methods for scoring the immunohistological stains semiquantitatively have been advocated in an attempt to render hormone receptor staining more objective [21, 22]. More recent data suggests that immunohistochemically detected ER shows a bimodal frequency distribution so that tumors are either negative or positive with $70 \%$ or more immunoreactive cells [23]. It has also been stated that the immunohistochemical reaction for ER is an all-or-none phenomenon [24], a claim supported by the observation that a significant benefit from adjuvant endocrine treatment is achieved in patients whose tumors contain only $1 \%$ of ER-positive cells [25].

\section{HER 2/neu (c-erbB-2)}

The Her2/neu gene is mapped on chromosome 17q12.21.32 and encodes a $185-\mathrm{kDa}$ transmembrane protein with $50 \%$ homology to the epidermal growth factor receptor. Her2/neu is able to operate in a ligand-independent manner, homodimerizing to elicit growth signals with the cell. The high-level expression resulting from gene amplification drives the basal level of Her2/neu activity above a threshold that can stimulate tumor growth. Since its discovery in breast cancer, Her2/neu has been shown to be a poor prognostic factor with overexpression of the protein or amplification of the gene correlating with poor outcome in patients with axillary lymph node metastases but not in patients with tumor-negative lymph nodes [26]. Subsequent data also revealed that Her2/neu overexpression/gene amplification was associated with a bad prognosis (high rate of recurrence and mortality) in patients with newly diagnosed breast cancer who were not receiving adjuvant systemic therapy [19].

Her2/neu represents a major milestone in breast cancer management as it has led to the development of Herceptin (trastuzumab), an effective antibody-based targeted therapy [27-29]. The humanized monoclonal antibody (in combination with chemotherapy) used as a first-line and adjuvant-setting agent has demonstrated a survival benefit in women with breast cancer that overexpresses the Her2/neu protein or in those who show amplification of the Her2/neu gene [30-33]. Her2/neu is thus a prognostic as well as predictive marker in breast cancer.

Several methods for assessing Her2/neu status are currently available, and each method has its proponents. Immunohistochemistry is the cheapest and most rapid procedure but suffers from a lack of standardization and the inability to control some of the more important variables that influence the preservation of antigen in fixed, processed tissues such as fixative, duration of fixation, and the lack of standardization of methods of antigen retrieval including time and temperature, tissue processing, and detection systems [17, 20]. Furthermore, cutoff values are arbitrarily set and scoring on a recommended 4-tiered system implies a continuum when the scores clearly do not [34]. Fluorescence in situ hybridization (FISH) is very sensitive and specific, but it is a time-demanding and expensive procedure. While they are more objective, fluorescence preparations fade, they require fluorescence microscopy, and image archiving is needed for permanent records. Chromogenic in situ hybridization (CISH) and silver-enhanced in situ hybridization (SISH) adopt the same procedure as FISH but employ a peroxidase reaction with diaminobenzidine as chromogen and silver precipitation in the case of SISH to provide a permanent preparation that can be viewed in bright-field microscopy. The introduction of microwave irradiation to the procedure enhances the consistency and visualization of signals [35]. When appropriately validated methods have been employed, a high level of concordance has been shown among all 4 methods of assay for Her2/neu [3638].

The examples of both ER and Her2/neu demonstrate the changing role of pathology in the assessment of breast tumors and in the design of personalized or tailored ther- 
apy. While tamoxifen and Herceptin have less toxic effects than chemotherapeutic agents do, they are not without complications. Tamoxifen has been linked to endometrial cancer, osteoporosis, thromboembolism, and effects on the central nervous system. Herceptin may be cardiotoxic and has been linked to allergic and pulmonary symptoms. Importantly, Herceptin is very expensive and only a fraction of women with breast cancer respond to this form of treatment so that it becomes an important role of pathology to identify the specific subset of patients who have the potential to benefit from this costly treatment that is not without complications, fulfilling the aim of personalized cancer care.

\section{The Role of Pathology in the Molecular Era}

Cancer is a disease of accumulating genetic alterations, and characterization of these alterations is predicted not only to expand our understanding of the genesis of specific cancers but also to help in terms of diagnosis, prognostication, and treatment. The rapid development of high-throughput molecular technologies has contributed significantly in the area of breast cancer by providing insights into the molecular complexity of the disease and a realization that the biological heterogeneity may have implications and opportunities for new forms of treatment.

Pioneering work from the Stanford group showed that breast cancer can be classified into molecularly distinct groups based on gene expression profiles and similarity to their normal counterparts [39]. By using a hierarchical clustering method and comparison to an 'intrinsic gene set', breast cancer was separated into 2 distinct molecular classes, i.e. an ER-positive/luminal class and an ER-negative class. The ER-positive/luminal class was divided into an ER-positive luminal A subtype and an ER-positive luminal B subtype, the latter having consistently poorer outcomes. Although some luminal B tumors can be identified by the expression of HER2, the major biological distinction between luminals A and B is the proliferation signature, with a higher expression of genes such as CCNB1, MKI67, and MYBL2 in luminal B tumors $[39,40]$. A recent report suggests that an immunohistochemistry-based surrogate assay can be used to distinguish between luminal A and luminal B tumors [41]. By employing a rabbit monoclonal antibody to Ki67 and a cutoff value of $13.25 \%$ together with antibodies to ER, PR, and HER2, it was possible to distinguish luminal A and luminal B breast cancer subtypes.

Changing Role of Pathology in

Breast Cancer
The ER-negative subtype encompassed 3 groups, i.e. one expressing genes characteristic of basal/myoepithelial cells (basal-like cancer), one over-expressing Her2/ neu, and the third with a gene expression profile similar to that of normal breast tissue, the latter consistently clustering with normal breast samples and fibroadenomas. Some of these groups were initially thought to be unstable, with some studies showing that the luminal class may comprise from 1 to 3 groups. The 'normal breast-like' cancers have been shown to correspond to the ER-negative class in most but not all studies [39, 42]. Subclusters or variations have occasionally been reported within the 'basal-like' group, but this group has uniformly been shown to belong to the ER-negative class. Importantly, the Her2/neu overexpressing and basal-like groups were shown to have poorer clinical outcomes. This molecular classification of breast cancer has to some extent been replicated with reverse transcriptase-polymerase chain reaction (RT-PCR) and a panel of selected genes [43, 44] or tissue microarrays (TMA) with selected antibodies [45-47].

\section{Basal-Like Breast Carcinoma}

Basal-like breast cancers were probably reported almost 2 decades ago as tumors with basal/myoepitheliallike characteristics that had a high nuclear grade, high mitotic activity, coexpression of high-molecular-weight cytokeratins and vimentin, and a lack of expression of ER and PR [44-51]. Basal-like tumors represent $16-37 \%$ of all breast cancers [42] and the resurgence of interest lies in gene profiling and the recognition that it is a group of tumors with a poor prognosis, with most recurrences occurring within the first 5 years following diagnosis [52, 53]. While patients with basal-like carcinomas respond to neoadjuvant chemotherapy [54-56], they paradoxically still have the worse outcome compared to patients with tumors belonging to other molecular groups $[45,54,55$, 57-59]. There is, however, circumstantial evidence suggesting that even this group of basal-like breast cancers is heterogeneous in terms of expression profiles, molecular genetic patterns [60], and clinical behavior $[45,46]$ as those patients with this tumor that show a complete pathological response following neoadjuvant chemotherapy have an excellent prognosis whereas those that display only a partial response have remarkably poor outcomes $[55,61]$. Importantly, patients with such tumors lack the benefit of currently available targeted therapy.

Basal-like breast cancers express genes previously associated with basal/myoepithelial cells including CK5 and CK17, integrin 4, laminin, CD117, $\alpha 6$ integrin, metallo- 
thionein IX, fatty acid-binding protein 7, P-cadherin, EGFR, caveolins 1 and 2, and nuclear factor $\kappa \mathrm{B}[39,62,63]$ as well as a variety of other genes including those associated with the activation of signaling pathways, proliferation and mitotic-checkpoint control genes and cell growthrelated genes, and genes involved in signal transduction and transcription factors. Basal-like tumors lack expression of the hormone receptors ER and PR, transcription factors, oncogenes such as Her2/neu, GATA3, basic transcription factor 3, X-box binding protein 1, RAB, FOXC1, FOXA1, TFF3, GRB7, GTPase-binding effector protein 1, fibronectin-1, and mucin-1 [39, 62-64]. In addition, these tumors often show TP53 gene mutations with expression of p53 by immunostaining and patients carrying BRCA1 mutations frequently show a basal-like phenotype [58, 65-68].

While the current 'gold standard' for the diagnosis of this group of cancers is microarray-based expression profiling, it is unlikely that this procedure will be employed as a routine diagnostic tool and surrogate markers will need to be developed for the 'intrinsic gene list' molecular taxonomy. RT-PCR-based methods have been developed and validated in archival, fixed, embedded tissue sections $[69,70]$; moreover, it appears that for the routine assessment immunohistochemistry is the most likely method for separation of the subtypes, although it should be noted that at present there is no internationally accepted definition of basal-like breast cancer. The basal-like phenotype correlates strongly with the lack of expression of ER, $\mathrm{PR}$, and Her2/neu, the so-called 'triple-negative' phenotype, although triple-negative and basal-like carcinomas are not exactly the same entity [54,71]. Basal-like tumors are also reported to show immunoreactivity in various proportions to antibodies against EGFR, CK5 (or CK5/6), CK14, P-cadherin, and CD117. In addition, other molecules that have been found in $35 \%$ or more of tested cases include laminin, vimentin, p53, BRCA-1, E-cadherin, MUC1, cyclin E, fascin, caveolin 1, VEGF, osteonectin, maspin, NGFR, nestin, $\alpha-\beta$-crystallin, and the $S$-phase kinase-associated protein Skp2 [reviewed in 72]. Recognizable proteins expressed in smaller numbers of cases include CD10, CD44, MET, and moesin.

The use of a panel of 4 antibodies to ER, Her2, CK5/6, and EGFR has been shown to have a sensitivity of $76 \%$ and specificity of $100 \%$ for basal-like breast cancers [73] confirming the prognostic relevance of this subgroup of cancers [74, 75]. Not all triple-negative breast cancers are basal-like and the expression of basal markers CK5/6 and/or EGFR has been shown to identify those patients with a significantly worse outcome than those triple-negative cases without these additional basal markers [74].
Attempts to correlate pathological features of basallike breast carcinomas with gene expression profiling have not always produced consistent results. Several histological features are described but these are not specific and have not been consistently identified [72]. The tumors have a high mitotic rate which correlates with the expression of proliferation marker Ki67, and an association with a larger tumor size would be intuitive but results have been conflicting. Interestingly, a meta-analysis of published breast cancer gene expression and the clinical data of 2,833 tumors suggested that the prognostic abilities of the main molecular subtypes of breast cancer including the basal-like subtype was due mainly to the detection of proliferation activity and that clinical variables such as tumor size and nodal status still added independent prognostic information to proliferation genes [76]. Basal-like tumors are more likely to have a pushing border than an infiltrating one and may show lymphoplasmacytic infiltration which, however, is not a specific feature and may be seen in other types of breast cancers. There may be central acellular areas of hyalinization or necrosis, and medullary and atypical medullary carcinomas, myoepithelial carcinomas, and metaplastic carcinomas may show the phenotype of basal-like tumors [72].

More recent refinements in the further characterization of this group of tumors through gene-expression profiling suggest that basal-like tumors are still heterogeneous and can be subdivided into at least 5 distinct subgroups [77]. Histologically it includes some special types of tumors associated with a good prognosis, such as medullary and adenoid cystic carcinomas [78], and the presence of central fibrosis and a paucity of lymphocytic infiltrate are predictors of distant metastasis in basal-like carcinomas [77].

\section{Quantitative Immunohistochemical Assays in TMA}

Identification of the molecular signatures in breast carcinoma is both expensive and time consuming, and it may be difficult to perform routinely. Recent developments suggest that the immunodetection of posttranscriptional protein products of some of the recognized prognostic indicator genes within tumor tissue may be economically and practically viable as the method employs commercially available antibodies and is applicable to fixed tissue sections in the form of TMA [79]. Based on reported immunohistochemical profiles of the various groups of breast carcinoma according to the new taxonomic classification derived from DNA array profiling 
into luminal, normal, and basal-like groups $[42,45,46$, $51,73,80-82$ ], a total of 42 immunohistochemical markers were quantitated by automated image analysis and shown to be predictive of disease outcome [78]. Analysis of 27 of the markers by logistic regression showed that 18, i.e. cMet, CD44v6, FAK, moesin, caveolin, CD117, CK14, CD10, p21, p27, pMAPK, pSTAT3, STAT1, SHARP2, FYN, ER, PR, and HER2, were $80.52 \%$ predictive of disease outcome, and when ER, PR, and HER2 were excluded this sensitivity fell to $78.9 \%$. This analysis guided the selection of patients requiring more aggressive therapy, and some of the markers in the signature may be indicative of tumor responsiveness to current chemotherapy or suggest new targets for specific therapies. It should be noted that TMA are subjected to the same reservations concerning the validity of quantitative immunohistochemistry previously alluded to $[16,17]$ including variations in section thickness [83]; this is even more so as the small cores of tumor tissue contained in the arrays have been subjected to different factors, some of which are pivotal to the preservation of tissue antigens.

\section{The Molecular Tools}

Breast cancer has been more extensively studied with molecular methods than has any other epithelial malignancy. The advent of molecular technology has allowed a systematic characterization of the molecular subtypes of breast cancer with a profound effect on the understanding of breast cancer. The molecular approach to the taxonomy and characterization of breast cancer has shown that the tumors in the distinct molecular groups differ in their clinical behaviors despite the fact that the classification system was not developed to predict outcomes. Molecular analysis has also provided insights into the genes that may drive each molecular subgroup. Not all tumors are the same in terms of their natural history or response to therapy. In addition, not all tumor cells, even within the same tumor, are the same as demonstrated by the recurrence of a 'resistant' clone of tumor cells following the initial treatment [84], prompting the need to attack the tumor on more than one front to reduce the possibility of evasion [85]. To date, the information derived from our understanding of the molecular features of breast cancer promises to provide additional diagnostic, prognostic, and predictive information. Importantly, such information allows a different approach to breast cancer that may, in the near future, facilitate the development of tailored therapy.

Changing Role of Pathology in

Breast Cancer

\section{Gene Expression Profiling Technology}

The generation of gene expression profiles from cultured cells and tissue samples is nowadays well established. Microarray-based analysis is one of the most frequently applied molecular tools for tumor gene expression profiling. In the majority of experiments, DNA fragments (e.g. cDNA and oligonucleotides) are spotted in an ordered pattern of grids onto a solid surface (a 'chip'). Each individual spot contains a high concentration of unique DNA fragments that map to specific genes or genomic sequences. The tested tissue RNA is extracted from tumor samples and reverse-transcribed into cDNA. The cDNA is labeled with fluorescent dyes and hybridized to the array or chips. The hybridization signals are detected by a laser scanner and the images are normalized in various ways. The relative expression levels obtained for individual genes are further clustered into groups of genes with similar or identical expression patterns for the analysis of biological relevance. The final results provide a genetic expression profile indicating overexpression, underexpression, no change, or complete absence for each gene in the tissue samples as compared to each other [86]. These were the studies employed by the Stanford group in the identification of molecular subgroups of breast cancer discussed above [39]. It has been recommended that supervised methods rather than cluster analyses be employed for class prediction and class comparison studies as they provide more powerful results for distinguishing predefined classes with a valid statistical identification of differentially expressed genes [87]. Such studies have resulted in the development of prognostic gene signatures which cannot be drawn using standard histopathological and immunohistochemical methods [88].

An important challenge for microarray analysis of disease tissues and cells is to define the relevance of associations between subsets, the differential expression of genes, and clinical features of disease. Therefore, the selection of clinical cases with a defined pathological diagnosis is critical for correlation analysis. Another challenge is the selection of small numbers of genes associated with specific pathological features. They have to be informative and clinically applicable. Yet another challenge is to determine how well RNA gene expression profiling correlates at the protein level. A lack of correlation may imply that the predictive property of the gene(s) is independent of gene function. For example, comparisons of messenger RNA and protein levels for the same tumors reported for lung cancer have demonstrated that only a small percentage of genes has a statistically significant

Pathobiology 2011;78:99-114 
correlation between the levels of their corresponding proteins and mRNAs [89]. All of these described roles can be fulfilled by the pathologist.

\section{Proteomic Profiling Technology}

DNA microarrays have a limited utility for the analysis of biological fluids and for uncovering assayable biomarkers in the fluid. Numerous alterations may occur in proteins that are not reflected in changes at the RNA level, providing a compelling rationale for a direct analysis of gene expression at the protein level. Unlike DNA microarrays, which provide only one measure, i.e. gene expression level or RNA levels, there is a need to address the many different features of proteins that can be altered in disease including not just the level of expression but also functional changes in the protein such as phosphorylation, glycosylation, acetylation, and other posttranslational modification changes in protein functions. In addition, determination of their selective interactions with other biomolecules, such as other proteins, antibodies, drugs, or various small ligands, can further complicate the analysis.

It is beyond the scope of this review to provide details of the rapidly developing proteome technology and only a brief listing of some will be done; furthermore, it is likely that no single technology will meet the needs of all types of proteomics-based investigations, from expression proteomics to functional proteomics, particularly as they relate to disease.

The 2-dimensional (2D) gel method is one of the mainstream technologies. In this method, proteins are separated in the first dimension according to their charge status by isoelectric focusing, followed by separation in the second dimension according to their molecular weights using polyacrylamide gel electrophoresis. The gels are then stained to visualize separated protein spots using either Coomassie, silver, or fluorescent stain. With this approach, up to 1,000 protein spots can be separated and visualized in a single experiment. Gels of different samples are compared and analyzed using computer software, and differentially expressed protein spots are then excised and identified by mass spectrometry (MS) [90-92]. The differential proteomic expression patterns and proteins can be useful as potential diagnostic or therapeutic markers.

Until relatively recently, profiling of protein expression in disease relied on the use of traditional 2D polyacrylamide gel electrophoresis (2D-PAGE). The technique is largely limited by the ability to separate only small portions of cellular proteins although more sensitive methods have been developed [93]. The differential comparison of protein expression profiling with $2 \mathrm{D}$ gel electrophoresis has shown promise for the identification of aberrantly expressed proteins in breast cancer [94].

Multiplexed in-line liquid separation systems coupled directly to MS using cellular lysates (LC-LC-LC-MS/MS) with affinity tagging may someday replace gel-based techniques such as 2D-PAGE $[95,96]$; however, 2D-PAGE is currently still reliable and is the most widely used proteomic separation and discovery technology. 2D-PAGE analysis has revealed a wealth of new information for potential biomarkers and therapeutic targets [97]. Adaptation of 2D-PAGE utilizing different fluorophores has been successfully employed for comparing different stages of breast cancer and nonneoplastic disease [98].

In exploring proteomic differences in the excised tissue sample, one major hurdle is the heterogeneity of the cell populations present. Tissue microdissection is required to analyze pure populations of cancer cells and to allow the pathologist to procure pure homogeneous cell populations from heterogeneous mixed cell populations in tissue samples [99]. This is achieved by laser capture microdissection (LCM) [100] and has been applied successfully to ductal carcinoma in situ [101].

Even with all the improvements that can be introduced, 2D gel electrophoresis will probably remain a rather low-throughput approach that requires a relatively large amount of sample, the latter posing a problem when there is limited clinical material. Furthermore, tissue heterogeneity complicates the analysis of clinical samples. Tissue microdissection circumvents this but further reduces the amount of sample available. Undoubtedly, various non-gel-based schemas that rely on the liquid-based separation of proteins or peptides with and without tagging will have utility for breast cancer proteomics, particularly given their potential automation.

Non-separation-based strategies, including direct profiling using MS or the use of protein microarrays, are important developments. MS applied to the in situ proteomic analysis of tissues allows the imaging of protein expression in normal and disease tissues [94]. In this method, frozen tissue is sectioned and applied on a matrix-assisted laser desorption/ionization (MALDI) plate and analyzed at regular spatial intervals. Comparisons of the mass spectra obtained at different intervals yields a spatial distribution of individual masses across the tissue section. Mass profiles of tissue sections from normal and disease tissues may be compared to detect altered protein expression. Such an approach has uncovered differences in protein expression between normal and tumor tissues that may have specificity for different tumor types [102]. 
Protein microarray-based profiling analysis represents a system that can profile the state of signaling pathways. This takes the form of reverse phase protein array (RPPA) technology $[103,104]$ which utilizes the small number of cells obtained from microdissected tissue. RPPA takes advantage of 2 existing enabling technologies, i.e. LCM and microarray fabrication. To prepare RPPA, pathologically relevant pure cell populations are isolated by LCM and lysed before being immobilized in an array configuration via a pin-based microarrayer onto glass-backed nitrocellulose slides. This procedure results in the separation of spots that contain the whole cellular protein repertoire corresponding to a given pathological state. Subsequently, each slide can be probed with an antibody detectable by amplified fluorescent, colorimetric, or chemiluminescent assays. The name 'reverse phase' is derived from the fact that this type of protein microarray immobilizes the protein to be analyzed. This is in contrast to conventional protein arrays that immobilize the antibody probe. RPPA denatures the protein lysate prior to immobilization and thus does not require labeling of the protein to be analyzed. Because individual protein entities are present in femtomolar or lower concentrations, an amplification system allows for the specific and sensitive detection of proteins [105].

Antibody-based protein arrays are produced by attaching several hundreds of proteins and peptides to the surface of glass slides. Arrays are incubated with patient tissue protein extracts, and fluorescent labels are used to detect antibody binding to specific proteins. Such microarrays represent a powerful tool for studying immune responses in a variety of tumors, including breast cancer.

\section{Comparative Genomic Hybridization and Array}

Comparative Genomic Hybridization

Comparative genomic hybridization $(\mathrm{CGH})$ provides an overview of changes in the DNA copy number across the whole genome $[106,107]$. It detects nonreciprocal or unbalanced structural changes where there is a physical change in the copy number of a region of the genome. CGH has helped to characterize the relationship between putative breast cancer precursors and invasive carcinoma as well as to identify genomic regions that may harbor tumor suppressor genes and oncogenes. There are numerous applications of CGH data for different types of breast lesions, ranging from benign entities to invasive breast cancers [108-111]. The use of LCM and reliable DNA amplification methods overcomes the effects of contaminants that adversely affect the ability to detect single copy number changes, and it is now routine to analyze very small lesions of pure populations $(90-100 \%)$ of morphologically defined cells in formalin-fixed, paraffin-embedded histological samples [112, 113].

The main disadvantage of metaphase CGH is the low resolution of its chromosomal hybridization; however, this limitation was resolved with the advent of microarray-based CGH. First described in 1997, matrix CGH (also known as array CGH) paved the way for the higherresolution detection of DNA copy number aberrations [114]. Array CGH is based on the same principles as metaphase CGH, except that the targets are mapped genomic clones instead of whole chromosomes. This approach introduced a new dimension to DNA copy number detection in terms of resolution and specificity of analysis. The first genome-wide array CGH analysis of DNA losses and gains used immobilized cDNA clones as hybridization targets. Using an array containing 3,360 human cDNAs (cDNA CGH) gene amplifications and deletions were mapped in breast cancer [115].

Array CGH technology is an important upgrade to the groundbreaking (conventional, metaphase chromosome) CGH technology and has eliminated the need to obtain metaphase spreads, dramatically increasing the resolution, importantly, in complex karyotypes, a hallmark of many tumors.

Array CGH has been useful in elucidating the extent of specific as well as recurrent aberrations in tumors such as those associated with mutations in BRCA1, BRCA2, or $P 53$ in both mice [116] and humans [117, 118].

$\mathrm{CGH}$ profiles have been used in the classification of breast tumors of unknown causality into BRCA1 mutation carriers and noncarriers [119] to delineate the relationship between synchronous, recurrent, and/or metastatic tumors [120-122] and to define the recurrent aberrations that appear to be associated with certain clinical types of breast cancer (e.g. ductal tumors), with the prognosis or clinical course, or both. One study [123] using metaphase CGH clearly demonstrated differential 5-year survival statistics (56 vs. 96\%) for distinct tumor types that were independent of more conventional markers such as grade and progesterone receptor or node status. Another report [124] used CGH to subclassify 86 breast tumors of grade III and basal type into groups with shorter (3.5 years) and longer (15 years) survival.

\section{Applications}

There have been many attempts to translate information derived from gene expression profiling into prognostic and predictive tools. The MammaPrint 70-gene signa- 
ture is one such attempt that originated from prognostic class prediction studies in breast cancer involving 25,000 genes studied by microarray in fresh frozen samples from 98 patients [125]. This assay, evaluated on patients with stage I or II breast cancer, regardless of nodal status, was shown to be a strong independent predictor of disease outcome [125]. A subsequent study demonstrated that patients stratified as low risk had an 88\% 10-year survival compared with $69 \%$ for the high risk group [126]. The assay is currently being assessed in the prospective MINDACT trial to determine treatment for those nodenegative, ER+ patients [127]. The Oncotype DX assay which, unlike the MammaPrint assay, employs fixed tissue and analyzes the level of expression of 16 outcomerelated genes and 5 reference genes by multiplex reverse transcription PCR and a mathematical algorithm to calculate a recurrence score [128] is another assay that is undergoing testing in a similar group of patients [129].

Three other well-known multigene assays for prognostication have undergone validation in independent data sets. A simple 2-gene signature that measures the ratio of the estrogen-regulated genes HOXB6 and $I L I 17 B R$ is significantly and independently associated with poorer disease-free survival in lymph node-negative, ER+, tamoxifen-treated patients with breast cancer $[130,131]$. The addition of 5 cell cycle-related genes improved the performance of the assay [132]. These 5 added genes reflect the more complex 97-gene genomic grade index that was developed to separate histological grade 2 tumors into low- and high-risk groups alongside grade 1 and grade 3 tumors [133]. In the case of the 76-gene Rotterdam signature, when applied to a purely ER+ population, 2 statistically distinct clinical outcomes were identified in both systemically untreated and tamoxifen-treated populations $[134,135]$. Interestingly, as the Rotterdam signature does not contain the same genes as either Oncotype DX or MammaPrint, and the genomic grade index is composed almost exclusively of proliferative genes, the overlap in results may be due to the strong dominance of proliferation-associated genes in all these signatures [133]. The strong influence of proliferation genes on clinical outcomes is further supported by other studies including a meta-analysis of published data [134, 135].

A different perspective of conventional tumor gene signatures is the stroma-derived prognostic predictor; it is generated by comparing normal and tumor stroma and stratifies the risk of progression using molecular markers that are independent of, but add power to, standard clinical prognostic factors and existing gene expression predictors [136]. The genes studied include those involved in immune reactions as well as angiogenesis and hypoxia. Not only are such assays of strong prognostic capacity but they also point to potential new targets for therapeutic agents.

There are a few emerging biomarkers with links to tissue stroma that may be of prognostic utility. Urokinase plasminogen activator (uPA) and plasminogen activator inhibitor (PAI-1) overexpression has consistently been associated with poor prognosis in early-stage breast cancer with combined high levels of both markers conferring a 2 - to 8-fold higher risk of recurrence and death [137-139]; unfortunately, fresh tissue is required for this assay. The mitotic process is another possible target for anticancer therapy [140]. Matrix metalloproteinases are recognized to degrade the basal lamina and surrounding stroma to promote tumor growth, and the spread, grade, and stage of breast cancer has been associated with MMP-2 and MMP-9. Phase III trials have failed to demonstrate significant improvement in outcome with MMP inhibitors [141]. Other targets of therapy include topoisomerase II $\alpha$ [142] and EGFR; the latter is inhibited by lapatinib, a tyrosine kinase inhibitor that is capable of inhibiting both EGFR and Her2/neu [143, 144].

The recent announcement of the successful use of poly adenosine diphosphate ribose polymerase (PARP) inhibitor (Olaparib, AZD2281) as a single agent in phase II trials in patients with advanced cancers with BRCA1 or BRCA2 mutations is particularly exciting as it exemplifies a new treatment discovered through molecular analyses [145]. In a single-arm trial, 12 of 19 patients with BRCA mutations showed a clinical benefit from treatment with radiological or tumor marker responses or meaningful disease stabilization; side effects from the oral treatment were minimal. PARP is an enzyme used by cancer cells to repair DNA damage, specifically the damage caused by chemotherapy. By inhibiting PARP, the neoplastic cells are more susceptible to the effects of treatment. PARP inhibitors are especially beneficial in patients who have deficient DNA repair systems such as $B R C A$ mutations, and they have been shown to be effective in a variety of tumors with deficient DNA repair systems, including breast cancer [145].

\section{Cancer Stem Cells}

The stem cell theory of cancer predicts that tumors contain a small number of tumor-initiating cells or cancer stem cells that drive tumor growth and populations of more differentiated nontumorigenic daughter cells 
analogous to the transit-amplifying and differentiated cells of normal tissue [146]. In fact, many observations suggest that there are analogies between normal stem cells and tumorigenic cells. Both normal stem cells and tumorigenic cells have extensive proliferative potential and the ability to give rise to new (normal or abnormal) tissues. Both tumors and normal tissues are composed of heterogeneous combinations of cells with different phenotypic characteristics and different proliferative potentials [146, 147]. Because most tumors have a clonal origin $[148,149]$, tumorigenic cancer cells must give rise to a phenotypically diverse progeny including cancer cells with indefinite proliferative potential as well as cancer cells with limited or no proliferative potential. This suggests that tumorigenic cancer cells undergo processes that are analogous to the self-renewal and differentiation of normal stem cells. Although some of the heterogeneity in tumors arises as a result of continuing mutagenesis, it is likely that heterogeneity also arises through the aberrant differentiation of cancer cells. It is well documented that many types of tumors contain cancer cells with heterogeneous phenotypes reflecting aspects of the differentiation that normally occurs in the tissues from which the tumors arise. The variable expression of normal differentiation markers by cancer cells in a tumor suggests that some of the heterogeneity in tumors arises as a result of the anomalous differentiation of tumor cells $[149,150]$.

In 2003 a report describing the prospective identification of human breast cancer stem cells changed the landscape of breast cancer research [151]. Using various human tumor samples (8 pleural effusions and 1 primary tumor) which were xenografted into the mammary glands of nonobese diabetic/severe combined immunodeficient mice, it was reported that a small population of CD44+/CD24-/Lin- human breast cancer cells were enriched for tumorigenic potential. Numerous recent studies have focused on testing the validity and universality of this model across tumor types of various tissues as well as its clinical implications. In line with these directions one study [152] examined possible correlations between the representation of tumor-initiating cells and classic molecular and histoclinical parameters that classify breast cancer into the molecular subtypes. Associations between the presence of cancer stem cells in clinical samples, aggressive tumor behavior and poor clinical outcome have been speculated upon, but so far only one study has shown such an association [153]. There is a need to develop a unique set of histological markers which can be confirmed across a broad range of breast tissue phenotypes in order to identify stem cell populations.

Changing Role of Pathology in

Breast Cancer
The cancer stem cell hypothesis has important implications for the development of cancer therapeutics. Recent evidence indicates that breast cancer stem cells [154] as well as cancer stem cells from other tumor types are relatively resistant to both radiation and chemotherapy [155]. There are several postulated mechanisms for this resistance. Cancer stem cells proliferate slowly, largely because they undergo an extended G0 phase of the cell cycle; this makes them resistant to cell-cycle-active chemotherapeutic agents. In addition, these cancer stem cells express increased adenosine triphosphate-binding cassette proteins known to efflux chemotherapeutic drugs. Indeed, ABCG2 or breast cancer resistance protein was initially identified in breast cancers. This molecule is overexpressed in stem cells and has been utilized to generate the so-called side population detected by flow cytometry [156]. In addition, enzymes such as ALDH that are highly expressed in stem cells are able to metabolize chemotherapeutic agents such as cyclophosphamide [157]. Cancer stem cells may also express increased levels of antiapoptotic molecules such as survivin and BCL2 family proteins [158]. Indeed, both in vitro and mouse models have provided evidence for the relative resistance of breast cancer stem cells to chemotherapy and radiation therapy [159, 160]. Recent neoadjuvant chemotherapy trials showing an increase in cells expressing stem cell markers in breast cancer cells following neoadjuvant chemotherapy support this concept [161]. These studies provide potential strategies for the development of cancer therapeutic targets, and the development of more effective therapies may require effective targeting of this cell population.

\section{Drug Discovery}

The discovery of new cancer drugs has traditionally relied on identifying chemical agents that target the unchecked proliferation of tumor cells. These efforts have resulted in a battery of chemotherapeutic agents whose mechanisms of action include direct or indirect DNA damaging agents, mitotic poisons, purine and pyrimidine antimetabolites, and inhibitors of steroid signaling [162]. At best, these drugs are blunt instruments. While they show some efficacy, they are not specific to tumor cells, thus causing the often severe side effects commonly associated with their use. Over the past 2 decades, the correlation between specific genetic lesions and cancer (e.g. specific chromosomal translocations associated with leukemia, or regions of gene amplification or loss in breast cancers) has prompted tremendous efforts geared

Pathobiology 2011;78:99-114 
toward identifying the proteins involved in mediating oncogenesis [163]. In turn, this has stimulated the development of selective small-molecule and antibody inhibitors of proteins such as EGFR, whose functions are causal in the disease's etiology $[164,165]$.

The rapid progress in genomics, proteomics, and mass spectroscopic technology has already begun to uncover novel functional pathways and therapeutic targets in breast cancer. Increased understanding of the genetic basis of different cancers has led to the development of a new generation of molecular targeted therapeutics such as Herceptin, which targets breast cancer cells that overexpress the HER2 protein. Drug targets in signal transduction pathways for tumor cell proliferation and angiogenesis have been developed with notable success and include erlotinib, cetuximab (EGFR), and bevacizumab (VEGF) [166]. However, regulation of the signal transduction pathways is complex and inhibition of these single targets may not always be effective (e.g. because of mutations in genes downstream from the receptor and because of alternate pathways to proliferation and survival or induction of feedback loops) or may lead to unwanted side effects (e.g. because the high doses required for inhibition lead to off-target activity or interference with normal cellular functions). Gene expression profiling methods and functional proteomics approaches are now available for looking at the effects of modulating multiple targets and pathways and designing drug discovery strategies based on effects across pathways and networks. In this regard, several approaches are being evaluated that use combinations of targeted therapies.

The development of new molecular drugs based on such a rational approach requires systematic progression through a number of predefined steps [167]. This process has been streamlined in recent years by the introduction of a range of new technologies and has been advanced considerably by progress in the molecular biology, genetics and pathology of cancer, systematic cancer genome sequencing, and expression profiling [168, 169]. The genes and pathways that are most commonly hijacked in cancer are most likely to provide potential therapeutic targets. Examples include the receptor tyrosine kinase Ras which regulates cell proliferation [170], control of the cell cycle by the cyclin-dependent kinase-retinoblastoma gene product axis [171], and the PI3 kinase pathway that governs cell survival and many other cell processes [172]. The frequency of a particular genetic abnormality in a specific tumor type and the linkage of the abnormality to clinical outcome, e.g. survival, can be very important in target selection. Once a potential target has been identi- fied, it is important that it is validated to confirm its role in tumorigenesis. This can be achieved by demonstration in model systems in which mutation or an altered expression of the gene produces the malignant phenotype [173].

The ongoing dissection of the genetics and proteomics of breast cancer should bring forth a range of additional new targets for drug design and discovery. By comprehensively inspecting the entire genome and proteome in breast cancer tissues or cells treated with drug or drug candidates, a detailed map of protein interactions related to breast cancer-associated pathways can be potentially obtained, facilitating drug development.

\section{Conclusions}

Pathology has been primarily concerned with diagnosis, pathogenesis, prognosis, and clinicopathological correlation. Immunohistochemical analysis of protein gene products has aided prognostication, and 3 markers, i.e. ER, PR, Her2/neu (and the more recently suggested Ki67), are routinely assessed as both prognostic and predictive markers in breast cancer. Molecular methods of analysis, including gene expression profiling and proteomics, have made important inroads into our understanding of the molecular pathways involved in the genesis of specific molecular subtypes of breast cancer and through gene profiling have identified at least 4 groups with different prognostic outcomes. The introduction of molecular techniques including CGH arrays, proteomics profiling, and sequencing technology, and the development of high-throughput technologies, has opened up new avenues of exploration into the genesis of breast cancer. More importantly, it has led to the realization that there are potentially new and specifically tailored avenues of treatment. Such developments have defined a new role for pathology that includes the prognostication and treatment of breast cancer.

\footnotetext{
References $>_{1}$ Bloom HJ, Richardson WW: Histological grading and prognosis in breast cancer: a study of 1,409 cases of which 359 have been followed for 15 years. Br J Cancer 1957;11: 359-377.

2 Blamey R: The design and clinical use of the Nottingham Prognostic Index in breast cancer. Breast 1996;5:156-157.

-3 Boyages J, Chua B, Taylor R, et al: Use of the St Galen classification for patients with node-negative breast cancer may lead to overuse of adjuvant chemotherapy. Br J Surg 2002;89:789-796.
} 
4 Goldhirsch A, Wood WC, Gelber RD, et al: Meeting highlights: updated international expert consensus on the primary therapy of early breast cancer. J Clin Oncol 2003;21: 3357-3365.

5 Adjuvant! online. http://www.adjuvanton line.com/index.jsp (accessed October 10, 2009).

6 Lipponen P, Aaltomaa S, Eskelinen M: The changing importance of prognostic factors in breast cancer during long-term follow-up. Int J Cancer 1992;51:698-702.

7 Decker T, Hungermann D, Bocker W: Prognostic and predictive factors of invasive breast cancer: update 2009 (in German). Pathologe 2009;30:49-55.

$>8$ Leong AS, Lee AK: Leader: Biological indices in the assessment of breast cancer. Clin Mol Pathol 1995;48:M221-M238.

-9 McGuire WL: Breast cancer prognostic factors: evaluation guidelines. J Natl Cancer Inst 1990;83:154-155.

10 Harbeck N, Jakesz R: St Gallen 2007: breast cancer treatment consensus report. Breast Care 2007;2:130-134.

- 11 Early Breast Cancer Trialists' Collaborative Group: Effects of chemotherapy and hormonal therapy for early breast cancer on recurrence and 15-year survival - an overview of the randomized trials. Lancet 2005;365 1687-1717.

12 Ring AE, Smith IE, Ashley S, et al: Oestrogen receptor status, pathological complete response and prognosis in patients receiving neoadjuvant chemotherapy for early breast cancer. Br J Cancer 2004;91:2012-2017.

-13 Colleoni M, Viale G, Zahrieh D: Chemotherapy is more effective in patients with breast cancer not expressing steroid hormone receptors: a study of preoperative treatment. Clin Cancer Res 2004;10:6622-6628.

$\checkmark 14$ Dowsett M, Houghton J, Iden C: Benefit from adjuvant tamoxifen therapy in primary breast cancer patients according to oestrogen receptor, progesterone receptor, EGF receptor and HER2 status. Ann Oncol 2006;17: 818-826.

$\checkmark 15$ Dowsett M, Cuzick J, Wale C, et al: Retrospective analysis of time to recurrence in the ATAC trial according to hormone receptor status: a hypothesis-generating study. J Clin Oncol 2005;23:7512-7517.

16 Leong AS: Quantitation in immunohistology - fact or fiction? A discussion of factors that influence results. Appl Immunohistochem Mol Morphol 2004;12:1-7.

17 Leong TY, Leong AS: Variables that influence outcomes in immunohistology. Aust J Med Sci 2007;28:47-59.

18 Misdiagnosed: anatomy of Newfoundland's cancer testing scandal. http://www.cbc.ca/ news/background/cancer/misdiagnosed. html\# (accessed October 2009).
19 Wolff AC, Hammond EH, Schwartz JN, et al: American Society of Clinical Oncology/College of American Pathologists guideline recommendations for human epidermal growth factor receptor 2 testing in breast cancer. J Clin Oncol 2007;25:118-145.

20 Leong AS: Pitfalls in diagnostic immunohistology. Adv Anat Pathol 2004;11:86-93.

21 Harvey JM, Clark GM, Osborne CK, Allred C: Estrogen receptor status by immunohistochemistry is superior to ligand-binding assay for endocrine response to adjuvant endocrine therapy in breast cancer. J Clin Oncol 1999; 17:1474-1481.

22 Regitnig P, Reiner A, Dinges HP, et al: Quality assurance for detection of estrogen and progesterone receptors by immunohistochemistry in Austrian pathology laboratories. Virchows Arch 202;441:328-334.

23 Collins LC, Botero ML, Schnitt SJ: Bimodal frequency distribution of estrogen receptor immunohistochemical staining results in breast cancer: an analysis of 825 cases. Am J Clin Pathol 2005;123:16-20.

24 Nadji M, Gomez-Fernandez C, Ganjei-Azar $\mathrm{P}$, Morales AR: Immunohistochemistry of estrogen and progesterone receptor reconsidered: experience with 5,993 breast cancers. Am J Clin Pathol 2005;123:21-27.

25 Elledge RM, Osborne CK: Oestrogen receptors and breast cancer. Br Med J 1997;314: 1843-1844.

26 Ross JS, Fletcher JA, Linette GP, et al: The Her2/gene and protein in breast cancer 2003: biomarker and target therapy. Oncologist 2003;8:307-325.

27 Carter P, Presta L, Gorman CM, et al: Humanization of an anti-p185HER2 antibody for human cancer therapy. Proc Natl Acad Sci USA 1992;89:4285-4289.

28 Baselga J, Perez EA, Peinkowski T, Bell R: Adjuvant trastuzumab: a milestone in the treatment of HER-2-positive early breast cancer. Oncologist 2006;11(suppl 1):4-12.

29 Emens LA: Trustuzumab: targeted therapy for the management of HER-2/neu-overexpressing metastatic breast cancer. Am J Ther 2005;12:243-253.

30 Slamon DJ, Leyland-Jones B, Shak S, et al: Use of chemotherapy plus a monoclonal antibody against HER2 for metastatic breast cancer that overexpresses HER2. N Engl J Med 2001;344:783-792.

- 31 Marty M, Cognetti F, Maraninchi D, et al: Randomized phase II trial of the efficacy and safety of trastuzumab combined with docetaxel in patients with human epidermal growth factor receptor 2-positive metastatic breast cancer administered as first-line treatment: the M77001 study group. J Clin Oncol 2005;23:4265-4274.

32 Romond EH, Perez EA, Bryant J, et al: Trastuzumab plus adjuvant chemotherapy for operable HER2-positive breast cancer. N Engl J Med 2005;353:1673-1684.
33 Piccart-Gebhart MJ, Procter M, LeylandJones B, et al: Trastuzumab after adjuvant chemotherapy in HER2-positive breast cancer. N Engl J Med 2005;353:1659-1672.

34 Leong TY, Leong AS: Controversies in the assessment of HER2: more questions than answers. Adv Anat Pathol 2006;13:263-270.

35 Leong AS, Haffajee Z, Clarke M: Microwave enhancement of CISH for Her2 oncogene. Appl Immunohistochem Mol Morphol 2007; 15:88-93.

36 Pothos A, Plastiras A, Vlachodimitropoulos $\mathrm{D}$, et al: Comparison of chromogenic in situ hybridization with fluorescence in situ hybridization and immunohistochemistry for the assessment of Her2/neu oncogene in archival material of breast carcinoma. Acta Histochem Cytochem 2008;41:59-64.

- 37 van de Vijver M, Bilous M, Hanna W, et al: Chromogenic in situ hybridization for the assessment of HER2 status in breast cancer: an international validation study. Breast Cancer Res 2007;9:R68.

- 38 Bilous M, Morey A, Armes J, et al: Chromogenic in situ hybridization testing for HER2 gene amplification in breast cancer produces highly reproducible results concordant with fluorescence in situ hybridization and immunohistochemistry. Pathology 2006;38: 130-134.

-39 Perou CM, Sorlie T, Elsen MB, et al: Molecular portraits of human breast tumors. Nature 2000;406:747-752.

$40 \mathrm{Hu}$ Z, Fan C, Oh DS, et al: The molecular portraits of breast tumors are conserved across microarray platforms. BMC Genomics 2006; 7:96.

41 Cheang MCU, Chia SK, Voduc D, et al: Ki67 index, HER2 status, and prognosis of patients with luminal B breast cancer. J Natl Cancer Inst 2009;101:736-750.

42 Rakha EA, Reis-Filho JS, Ellis IO: Impact of basal-like breast carcinoma determination for a more specific therapy. Pathobiology 2008;75:95-103.

43 Mullins M, Perreard L, Quackenbush JF, et al: Agreement in breast cancer classification between microarray and quantitative reverse transcription PCR from fresh frozen and formalin-fixed, paraffin-embedded tissues. Clin Chem 2007;53:1273-1279.

44 Chanrion M, Fontaines H, Rodriguez C, et al: A new molecular breast cancer subclassification defined from a large scale real-time quantitative RT-PCR study. BMC Cancer 2007;7:39.

45 Abd El-Rehim DM, Ball G, Pinder SE, et al: High-throughput protein expression analysis using tissue microarray technology of a large well-characterised series identifies biologically distinct classes of breast cancer confirming recent cDNA expression analysis. Int J Cancer 2005;116:340-350. 
-46 Makretsov NA, Huntsman DG, Nielsen TO, et al: Hierarchical clustering analysis of tissue microarray immunostaining data identifies prognostically significant groups of breast carcinoma. Clin Cancer Res 2004;10: 6143-6151.

-47 Dolled-Filhart M, Ryden L, Cregger M, et al: Classification of breast cancer using genetic algorithms and tissue microarrays. Clin Cancer Res 2006;12:6459-6468.

48 Raymond WA, Leong AS: Vimentin - a new prognostic parameter in breast carcinoma. J Pathol 1989;158:107-114.

49 Leong AS, Raymond WA: Update: prognostic parameters in breast carcinoma. Pathology 1989;21:169-175.

-50 Dairkee SH, Ljung BM, Smith H, Hackett A: Immunolocalization of a human basal epithelium specific keratin in benign and malignant breast disease. Breast Cancer Res Treat 1987;10:11-20.

-51 Santini D, Ceccarelli C, Taffurelli M, et al: Differentiation pathways in primary invasive breast carcinoma as suggested by intermediate filament and biopathological marker expression. J Pathol 1996;179:386-391.

-52 Jumppanen M, Gruvberger-Saal S, Kauraniemi P, et al: Basal-like phenotype is not associated with patient survival in estrogen receptor-negative breast cancers. Breast Cancer Res 2007;9:R16.

53 Pulford LG, Reis-Filho JS, Ryder K, et al: Basal-like grade III invasive ductal carcinoma of the breast: patterns of metastasis and longterm survival. Breast Cancer Res 2007;9:R4.

- 54 Rouzier R, Perou CM, Symmans WF, et al: Breast cancer molecular subtypes respond differently to preoperative chemotherapy. Clin Cancer Res 2005;11:5678-5685.

55 Carey LA, Dees EC, Sawyer L, et al: The triple negative paradox: primary tumor chemosensitivity of breast cancer subtypes. Clin Cancer Res 2007;13:2329-2334.

56 Dent R, Trudeau M, Pritchard KL, et al: Triple-negative breast cancer: clinical features and patterns of recurrence. Clin Cancer Res 2007;13:4429-4434.

57 Abd El-Rehim DM, Pinder SE, Paish CE, et al: Expression of luminal and basal cytokeratins in human breast carcinoma. J Pathol 2004;203:661-671.

- 58 Rakha EA, Putti TC, Abd El-Rehim DM, et al: Morphological and immunophenotypic analysis of breast carcinomas with basal and myoepithelial differentiation. J Pathol 2006; 208:495-506.

59 Banerjee S, Reis-Filho JS, Ashley S, et al: Basal-like breast carcinomas: clinical outcome and response to chemotherapy. J Clin Pathol 2006;59:729-735.

-60 Jones C, Ford E, Gillett C, et al: Molecular cytogenetic identification of subgroups of grade III invasive ductal breast carcinomas with different clinical outcomes. Clin Cancer Res 2004;10:5988-5997.
61 Liedtke C, Mazouni C, Hess KR, et al: Response to neoadjuvant therapy and longterm survival in patients with triple-negative breast cancer. J Clin Oncol 2008;26:12751281.

62 Savage K, Lambros MB, Robertson D, et al: Caveolin 1 is overexpressed and amplified in a subset of basal-like and metaplastic breast carcinoma: a morphologic, ultrastructural, immunohistochemical, and in situ hybridization analysis. Clin Cancer Res 2007;13: 90-101.

63 Yehiely F, Moyano JV, Evans JR, et al: Deconstructing the molecular portrait of basal-like breast cancer. Trends Mol Med 2006;12:537544.

64 Molokentin JD: The zinc finger containing transcription factors GATA-4, -5 , and -6 : ubiquitously expressed regulators of tissue specific gene expression. J Biol Chem 2000; 275:38949-38952.

65 Sorlie T, Perou CM, Tibshirani R, et al: Gene expression patterns of breast carcinomas distinguish tumor subclasses with clinical implications. Proc Natl Acad Sci USA 2001; 98:10869-10874.

66 Sorlie T, Tibshirani R, Parker J, et al: Repeated observation of breast tumor subtypes in independent gene expression data sets. Proc Natl Acad Sci USA 2003;100:8418-8423.

-67 Tirkkonen M, Johannsson O, Agnarsson BA, et al: Distinct somatic genetic changes associated with tumor progression in carriers of BRCA1 and BRCA2 germ-line mutations. Cancer Res 1997;57:1222-1227.

68 Jonsson G, Naylor TL, Vallon-Christersson $J$, et al: Distinct genomic profiles in hereditary breast tumors identified by array-based comparative genomic hybridization. Cancer Res 2005;65:7612-7621.

69 Parker J, Mullins M, Cheang MC, et al: A supervised risk predictor of breast cancer based on biological subtypes. J Clin Oncol 2008;26(suppl 15):43s.

70 Perreard L, Fan C, Quackenbush JF, et al: Classification and risk stratification of invasive breast carcinomas using real-time quantitative RT-PCR assay. Breast Cancer Res 2006;8:R23.

71 Calza S, Hall P, Auer G, et al: Intrinsic molecular signature of breast cancer in a population-based cohort of 412 patients. Breast Cancer Res 2006;8:R34.

72 Fadare O, Tavassoli FA: The phenotypic spectrum of basal-like breast cancers: a critical appraisal. Adv Anat Pathol 2007;14:358373.

73 Nielsen TO, Hsu FD, Jensen K, et al: Immunohistochemical and clinical characterization of the basal-like subtype of invasive breast carcinoma. Clin Cancer Res 2004;10: 5367-5374.

74 Cheang MC, Vodue D, Bajdik C, et al: Basallike breast cancer defined by five biomarkers has superior prognostic value than triplenegative phenotype. Clin Cancer Res 2008; 14:1368-1376.
75 Tan DS, Marchio C, Jones RL, et al: Triple negative breast cancer: molecular profiling and prognostic impact in adjuvant anthracycline-treated patients. Breast Cancer Res Treat 2008;111:27-44.

76 Wirapati P, Sotiriou C, Kumkel S, et al: Metaanalysis of gene expression profiles in breast cancer: toward a unified understanding of breast cancer subtyping and prognosis signatures. Breast Cancer Res 2008;10:R65.

77 Kreike B, van Kouwenhove M, Horlings H, et al: Gene expression profiling and histopathological characterization of triple-negative/ basal-like breast carcinomas. Breast Cancer Res 2007;9:R65.

-78 Weigelt B, Horlings HM, Kreike B, et al: Refinement of breast cancer classification by molecular characterization of histological specific types. J Pathol 2008;216:141-150.

79 Charpin C, Secq V, Giusiano S, et al: A signature predictive of disease outcome in breast carcinomas, identified by quantitative immunocytochemical assays. Int J Cancer 2008;124:2124-2134.

80 Jacquemier J, Ginestier C, Rougemont J, et al: Protein expression profiling identifies subclasses of breast cancer and predicts prognosis. Cancer Res 2005;65:767-779.

81 Livasy CA, Karaca G, Nanda R, et al: Phenotypic evaluation of the basal-like subtype of invasive breast carcinoma. Mod Pathol 2006; 19:264-271.

82 Reis-Filho JS, Tutt AN: Triple negative tumors: a critical review. Histopathology 2008; 52:108-118.

83 Leong AS: Quantitative immunohistology: tissue section thickness, another glitch in the path to standardization. Appl Immunohistochem Mol Morphol 2009;17:465-469.

-84 Gonzalez-Angulo AM, Morales-Vasquez F, Hortobagyi GN: Overview of resistance to systemic therapy in patients with breast cancer. Adv Exp Med Biol 2007;608:1-22.

$\checkmark 85$ Petrelli A, Giordano S: From single- to multitarget drugs in cancer therapy: when a specificity becomes an advantage. Curr Med Chem 2008; 15:422-432.

$\$ 86$ Brown PO, Botstein D: Exploring the new world of the genome with DNA microarrays. Nat Genet 1999;21:33-37.

87 Simon R, Radmacher D, Dobbin K, McShane LM: Pitfalls in the use of DNA microarray data for diagnostic and prognostic classification. J Natl Cancer Inst 2003;95:14-18.

88 Huang E, Cheng SH, Dressman H, et al: Gene expression predictors of breast cancer outcomes. Lancet 2003;361:1590-1596.

89 Chen G, Gharib TG, Huang CC, et al: Proteomic analysis of lung adenocarcinoma: identification of a highly expressed set of proteins in tumors. Clin Cancer Res 2002;8: 2290-2305.

90 Kumarathasan P, Mohottalage S, Goegan P, Vincent R: An optimized protein in-gel digestion method for reliable proteome characterization by MALDI-TOF-MS analysis. Anal Biochem 2005;346:85-89. 
-91 Meunier B, Bouley J, Piec I, et al: Data anal- 105 Torhorst J, Bucher C, Kononen J, et al: Tisysis methods for detection of differential protein expression in two-dimensional gel electrophoresis. Anal Biochem 2005;340: 226-230.

92 Hanash S: 2-D or not 2-D - is there a future for 2-D gels in proteomics? Insights from the York proteomic meeting. Proteomics 2001;1:635-637.

$\checkmark 93$ Gorg A, Obermaier C, Boguth G, et al: The current state of two-dimensional electrophoresis with immobilized $\mathrm{pH}$ gradients. Electrophoresis 2000;21:1202-1209.

$\checkmark 94$ Bisca A, D’Ambrosio C, Scaloni A, et al: Proteomic evaluation of core biopsy specimens from breast lesions. Cancer Lett 2004; 204:79-86.

95 Shen Y, Tolic N, Zhao R, et al: Ultrasensitive proteomics using high-efficiency on-line micro-SPE-naoLC-nanoESI MS and MS/ MS. Anal Chem 2001;21:198-210.

\$96 Wang Y, Rudnick P, Evans E, Zhuang Z, et al: Proteome Analysis of microdissected tumor tissue using a capillary isoelectric focusing-based multidimensional separation platform coupled with ESI-tandem MS. Anal Chem 2005;77:6549-6556.

$\checkmark 97$ Celis JE, Gromov P, Cabezon T, et al: Proteomic characterization of the interstitial fluid perfusing the breast tumor microenvironment: a novel resource for biomarker and therapeutic target discovery. Mol Cell Proteomics 2004;3:327-344.

-98 Somiari RI, Sullivan A, Russell S, et al: High-throughput proteomic analysis of human infiltrating ductal carcinoma. Proteomics 2003;3:1863-1873.

$>99$ Zhuang Z, Bertheau P, Emmert-Buck M, et al: A microdissection technique for archival DNA analysis of specific cell populations in lesions less than one millimeter in size. Am J Pathol 1995;146:620-625.

- 100 Emmert-Buck MR, Bonner RF, Smith PD, et al: Laser capture microdissection. Science 1996;274:998-1001.

-101 Wulfkuhle JD, Mclean KC. Pawetetz CP, et al: Proteomics of human breast ductal carcinoma in situ. Cancer Res 2002;62:67406747.

102 Stoeckli M, Chaurand P, Hallahan DE, Caprioli RM: Imaging mass spectrometry: a new technology for the analysis of protein expression in mammalian tissues. Nat Med 2001;7:493-496.

103 Paweletz CP, Charboneau L, Bichsel VE, et al: Reverse phase protein microarrays which capture disease progression show activation of prosurvival pathways at the cancer invasion front. Oncogene 2001;20:19811989.

104 Liotta LA, Espina V, Mehta AI, et al: Protein microarrays: meeting analytical challenges for clinical applications. Cancer Cell 2003; 3:317-325 sue microarrays for rapid linking of molecular changes to clinical endpoints. Am J Pathol 2001;159:2249-2256.

106 Kallioniemi A, Kallioniemi OP, Sudar D, et al: Comparative genomic hybridization for molecular cytogenetic analysis of solid tumors. Science 1992;258:818-821.

107 Weiss MM, Hermsen MA, Meijer GA, et al: Comparative genomic hybridization. Mol Pathol 1999;52:243-251.

108 Aubele M, Mattis A, Zitzelsberger H, et al: Extensive ductal carcinoma in situ with small foci of invasive ductal carcinoma: evidence of genetic resemblance by CGH. Int J Cancer 2000;85:82-86.

109 Buerger H, Simon R, Schafer KL, et al: Genetic relation of lobular carcinoma in situ, ductal carcinoma in situ, and associated invasive carcinoma of the breast. Mol Pathol 2000;53:118-121.

110 Cingoz S, Altungoz O, Canda T, et al: DNA copy number changes detected by comparative genomic hybridization and their association with clinicopathologic parameters in breast tumors. Cancer Genet Cytogenet 2003;145:108-114.

111 Jones C, Ford E, Gillett C, et al: Molecular cytogenetic identification of subgroups of grade III invasive ductal breast carcinomas with different clinical outcomes. Clin Cancer Res 2004;10:5988-5997.

112 Jones C, Damiani S, Wells D, et al: Molecular cytogenetic comparison of apocrine hyperplasia and apocrine carcinoma of the breast. Am J Pathol 2001;158:207-214.

113 Lage JM, Leamon JH, Pejovic T, et al: Whole genome analysis of genetic alterations in small DNA samples using hyperbranched strand displacement amplification and array-CGH. Genome Res 2003;13:294-307.

114 Solinas-Toldo S, Lampel S, Stilgenbauer S, et al: Matrix-based comparative genomic hybridization: biochips to screen for genomic imbalances. Genes Chromosomes Cancer 1997;20:399-407.

115 Pollack JR, Perou CM, Alizadeh AA, et al: Genome-wide analysis of DNA copy-number changes using cDNA microarrays. Nat Genet 1999;23:41-46.

116 Weaver Z, Montagna C, Xu X, et al: Mammary tumors in mice conditionally mutant for Brcal exhibit gross genomic instability and centrosome amplification yet display a recurring distribution of genomic imbalances that is similar to human breast cancer. Oncogene 2002;21:5097-5107.

117 Jonsson G, Naylor TL, Vallon-Christersson $\mathrm{J}$, et al: Distinct genomic profiles in hereditary breast tumors identified by arraybased comparative genomic hybridization. Cancer Res 2005;65:7612-7621.

118 Tirkkonen M, Kainu T, Loman N, et al: Somatic genetic alterations in BRCA2-associated and sporadic male breast cancer. Genes Chromosomes Cancer 1999;24:5661.
19 Wessels LF, van Welsem T, Hart AA, et al: Molecular classification of breast carcinomas by comparative genomic hybridization: a specific somatic genetic profile for BRCA1 tumors. Cancer Res 2002;62:71107117.

120 van Beers EH, van Welsem T, Wessels LF, et al: Comparative genomic hybridization profiles in human BRCA1 and BRCA2 breast tumors highlight differential sets of genomic aberrations. Cancer Res 2005;65: $822-827$.

121 Nyante SJ, DeVries S, Chen YY, Hwang ES: Array-based comparative genomic hybridization of ductal carcinoma in situ and synchronous invasive lobular cancer. Hum Pathol 2004;35:759-763.

122 Seo MY, Rha SY, Yang SH, et al: The pattern of gene copy number changes in bilateral breast cancer surveyed by cDNA microarray-based comparative genomic hybridization. Int J Mol Med 2004;13:17-24.

123 Rennstam K, Ahlstedt-Soini M, Baldetorp $B$, et al: Patterns of chromosomal imbalances defines subgroups of breast cancer with distinct clinical features and prognosis: a study of 305 tumors by comparative genomic hybridization. Cancer Res 2003; 63:8861-8868.

124 Jones C, Ford E, Gillett C, et al: Molecular cytogenetic identification of subgroups of grade III invasive ductal breast carcinomas with different clinical outcomes. Clin Cancer Res 2004;10:5988-5997.

125 Van't Veer LJ, Dai H, van de Vijer MJ, et al: Gene expression profiling predicts clinical outcomes of breast cancer. Nature 2002; 415:530-536.

126 Buyse M, Loi S, van't Veer LJ, et al: Validation and clinical utility of a 70-gene prognostic signature for women with node-negative breast cancer. J Natl Cancer Inst 2006; 98:1183-1192.

127 Sparano JA, Paik S: Development of the 21gene assay and its application in clinical practice and clinical trials. J Clin Oncol 2008;26:721-728.

128 Paik S, Shak S, Tang G, et al: A multigene assay to predict recurrence of tamoxifentreated, node-negative breast cancer. $\mathrm{N}$ Engl J Med 2004;351:2817-2826.

129 Paik S, Tang G, Shak S, et al: Gene expression and benefit of chemotherapy in women with node-negative, estrogen receptor-positive breast cancer. J Clin Oncol 2006;24: 3726-3734.

130 Ma XJ, Hilsenback SG, Wang W, et al: The HOX-B13:IL17BR expression index is a prognostic factor in early stage breast cancer. J Clin Oncol 2006;24:4611-4619.

131 Wang Z, Dahiya S, Provencher H, et al: The prognostic biomarkers HOXB13, IL17BR and $\mathrm{CHDH}$ are regulated by estrogen in breast cancer. Clin Cancer Res 2007;13: 6327-6334. 
132 Ma XJ, Salunga R, Dahiya S, et al: A 144 Reid A, Vidal L, Shaw H, de Bono J: Dual five-gene molecular grade index and HOXB13:IL17BR are complementary prognostic factors in early stage breast cancer. Clin Cancer Res 2008;14:2601-2608.

133 Sotiriou C, Wirapati P, Loi S, et al: Comprehensive analysis integrating both clinicopathological and gene expression data in more than 1,500 samples: proliferation captured by gene expression grade index appears to be the strongest prognostic factor in breast cancer. J Clin Oncol 2006;24:4S.

134 Wang Y, Klijn JG, Zhang Y, et al: Gene-expression profiles to predict distant metastasis of lymph-node-negative primary breast cancer. Lancet 2005;365:671-679.

135 Loi S, Haibe-Kains B, Desmedi C, et al: Definition of clinically distinct molecular subtypes in estrogen receptor-positive breast carcinomas through genomic grade. J Clin Oncol 2007;25:1239-1246.

$\checkmark 136$ Desmedt C, Haibe-Kains B, Wirapati P, et al: Biological processes associated with breast cancer clinical outcome depend on the molecular subtypes. Clin Cancer Res 2008; 14:5158-5165.

137 Finak G, Bertos N, Pepin F, et al: Stromal gene expression predicts clinical outcome in breast cancer. Nat Med 2008;14:518-527.

138 Duffy MJ: Urokinase plasminogen activator and its inhibitor, PAI-1, as prognostic markers in breast cancer: from pilot to level 1 evidence studies. Clin Chem 2002;48: 1194-1197.

-139 Eppenberger U, Kuang W, Schlaeppi JM, et al: Markers of tumor angiogenesis and proteolysis independently define high- and low-risk subsets of node-negative breast cancer patients. J Clin Oncol 1998;16:31293136.

140 Janicke F, Prechit A, Thompsen C, et al: Randomized adjuvant chemotherapy trial in high-risk, lymph node-negative breast cancer patients identified by urokinasetype plasminogen activator and plasminogen activator inhibitor type 1. J Natl Cancer Inst 2001;93:911-920.

141 Sudakin V, Yen TJ: Targeting mitosis for anti-cancer therapy. BioDrugs 2007;21: 225-233.

142 Hidalgo M, Eckhardt SG: Development of matrix metalloproteinase inhibitors in cancer therapy. J Natl Can Inst 2001;93:178193.

143 Pritchard KI, Messersmith H, Elavathil L, et al: HER-2 and topoisomerase II as predictors of response to chemotherapy. J Clin Oncol 2008;26:736-744. inhibition of ErbB1 (EGFR/HER1) and ErbB2 (HER2/neu). Eur J Cancer 2007;43: 481-489.

145 Fong PC, Boss DS, Yap TA, et al: Inhibition of poly(ADP-ribose) polymerase in tumors from BRCA mutation carriers. N Engl J Med 2009;361:123-134.

146 Reya T, Morrison SJ, Clarke MF, Weissman IL: Stem cells, cancer, and cancer stem cells. Nature 2001;414:105-111.

147 Heppner GH: Tumor heterogeneity. Cancer Res 1984;44, 2259-2265.

148 Nowell PC: Mechanisms of tumor progression. Cancer Res 1986;46:2203-2207.

149 Fialkow PJ: Clonal origin of human tumors. Biochim Biophys Acta 1976;458:283-321.

150 Sell S, Pierce GB: Maturation arrest of stem cell differentiation is a common pathway for the cellular origin of teratocarcinomas and epithelial cancers. Lab Invest 1994;70: 6-22.

151 Al-Hajj M, Wicha SM, Benito-Hernandez A, et al: Prospective identification of tumorigenic breast cancer cells. Proc Natl Acad Sci USA 2003;100:3983-3988.

152 Honeth G, Bendahl PO, Ringnér M, et al: The CD44+/CD24- phenotype is enriched in basal-like breast tumors. Breast Cancer Res 2008;10:R53.

153 Ginestier C, Hur MH, Charafe-Jauffret E, et al: ALDH1 is a marker of normal and malignant human mammary stem cells and a predictor of poor clinical outcome. Cell Stem Cell 2007;1:555-567.

154 Sakariassen PO, Immervoll H, Chekenya $\mathrm{M}$ : Cancer stem cells as mediators of treatment resistance in brain tumors: status and controversies. Neoplasia 2007;9:882-892.

155 Tang C, Chua CL, Ang BT: Insights into the cancer stem cell model of glioma tumorigenesis. Ann Acad Med Singapore 2007;36: 352-357.

156 Kim M, Turnquist H, Jackson J, et al: The multidrug resistance transporter ABCG2 (breast cancer resistance protein 1) effluxes Hoechst 33342 and is overexpressed in hematopoietic stem cells. Clin Cancer Res 2002;8:22-28.

157 Smalley MJ, Clarke RB: The mammary gland 'side population': a putative stem/ progenitor cell marker? J Mammary Gland Biol Neoplasia 2005;10:37-47.

158 Litingtung Y, Lawler AM, Sebald SM, et al: Growth retardation and neonatal lethality in mice with a homozygous deletion in the C-terminal domain of RNA polymerase II. Mol Gen Genet 1999;261:100-105.
159 Shafee N, Smith CR, Wei S, et al: Cancer stem cells contribute to cisplatin resistance in Brca1/p53-mediated mouse mammary tumors. Cancer Res 2008;68:3243-3250.

160 Hambardzumyan D, Squatrito M, Holland EC: Radiation resistance and stem-like cells in brain tumors. Cancer Cell 2006;10:454456.

161 Li X, Lewis MT, Huang J, et al: Intrinsic resistance of tumorigenic breast cancer cells to chemotherapy. J Natl Cancer Inst 2008; 100:672-679.

162 Bast RC Jr, Kufe DW Jr, Pollock RE, et al: (eds) Cancer Medicine. Hamilton, Decker, 2000, pp 612-699.

163 Reddy A, Kaelin WG Jr: Using cancer genetics to guide the selection of anticancer drug targets. Curr Opin Pharmacol 2002;2: 366-373.

164 Shawver LK, Slamon D, Ullrich A: Smart drugs: tyrosine kinase inhibitors in cancer therapy. Cancer Cell 2002;1:117-123.

165 Brekke OH, Sandlie I: Therapeutic antibodies for human diseases at the dawn of the twenty-first century. Nat Rev Drug Discov 2003;2:52-62.

166 Kelloff GJ, Bast RC Jr, Coffey DS, et al: Biomarkers, surrogate end points, and the acceleration of drug development for cancer prevention and treatment: an update prologue. Clin Cancer Res 2004;10:3881-3884.

167 Garrett MD, Workman P: Discovering novel chemotherapeutic drugs for the third millennium. Eur J Cancer 1999;35:20102030.

168 Futreal PA, Kasprzyk A, Birney E, et al: Cancer and genomics. Nature 2001;409. 850-852.

169 Davies H, Bignell GR, Cox C, et al: Mutations of the BRAF gene in human cancer. Nature 2002;417:949-954.

170 Marshall CJ: Opportunities for pharmacological intervention in the ras pathway. Ann Oncol 1995;6(suppl 1):63-67.

171 Lundberg AS, Weinberg RA: Control of the cell cycle and apoptosis. Eur J Cancer 1999; 35:1886-1894.

172 Vivanco I, Sawyers CL: The phosphatidylinositol 3-Kinase AKT pathway in human cancer. Nat Rev Cancer 2002;2:489501.

173 Workman P: New drug targets for genomic cancer therapy: successes, limitations, opportunities and future challenges. Curr Cancer Drug Targets 2001;1:33-47. 